\title{
Linking genotype and phenotype in an economically viable propionic acid biosynthesis process
}

\author{
Carlos H. Luna-Flores ${ }^{1}$, Chris C. Stowers ${ }^{3}$, Brad M. Cox ${ }^{3}$, Lars K. Nielsen ${ }^{1,2}$ and Esteban Marcellin ${ }^{1,2^{*}}$
}

\begin{abstract}
Background: Propionic acid (PA) is used as a food preservative and increasingly, as a precursor for the synthesis of monomers. PA is produced mainly through hydrocarboxylation of ethylene, also known as the 'oxo-process'; however, Propionibacterium species are promising biological PA producers natively producing PA as their main fermentation product. However, for fermentation to be competitive, a PA yield of at least $0.6 \mathrm{~g} / \mathrm{g}$ is required.

Results: A new strain able to reach the required yield was obtained using genome shuffling. To gain insight into the changes leading to the improved phenotype, the genome of the new strain was sequenced, and metabolomics and transcriptomics data were obtained. In combination, the data revealed three key mutations: (i) a mutation in the promoter region of a sugar transporter which enables an increase in the uptake rate of sucrose; (ii) a mutation in a polar amino acid transporter which improves consumption of amino acids and acid tolerance; and (iii) a mutation in a gene annotated as a cytochrome $\mathrm{C}$ biogenesis gene, which is likely responsible for the coupling of the Wood-Werkman cycle to ATP production were responsible for the phenotype. The bioprocess was further enhanced with a feeding strategy that achieved $70 \mathrm{~g} / \mathrm{L}$ of product. The proposed bioprocess is expected to outperform the economics of the current'oxo-process' by 2020.
\end{abstract}

Conclusions: In this study, using genome shuffling, we obtained a strain capable of producing PA exceeding the commercial needs. The multiomics comparison between the novel strain and the wild type revealed overexpression of amino acid pathways, changes in sucrose transporters and an increased activity in the methylglyoxal and the glucuronate interconversion pathways. The analysis also suggests that a mutation in the cytochrome $\mathrm{C}$ biogenesis gene, coupled with ATP production through the Wood-Werkman cycle, may be responsible for the increased PA production.

Keywords: Propionic acid, Propionibacterium, Genome shuffling, Genomics, Metabolomics, Transcriptomics

\section{Background}

Traditionally derived from fossil fuels, propionic acid (PA) is used in the food industry as a preservative. Due to its three-carbon backbone, PA has found increased use for the synthesis of monomers and polymers. As a result, the market for PA has steeply grown $5.1 \%$ per annum to over 350,000 tonnes/year over the past decade. This increased demand results in the need for new PA

\footnotetext{
*Correspondence: e.marcellin@uq.edu.au

${ }^{1}$ Australian Institute for Bioengineering and Nanotechnology (AIBN), The

University of Queensland, Brisbane, QLD 4072, Australia

Full list of author information is available at the end of the article
}

infrastructure and more sustainable production routes [1]. Bacterial fermentation addresses many environmental concerns and offers a sustainable alternative for its production. Propionibacteria naturally produce PA as their main fermentation product using the Wood-Werkman cycle $[2,3]$. Recent economic and ecological assessment called for a yield of $0.6 \mathrm{~g} / \mathrm{g}$ for an economically viable scalable process $[1,4]$.

PA yield determines economic viability as the feedstock and the downstream purification process contributes largely to the production cost of PA biosynthesis [1]. Given limitations in the availability of tools for rational 
strain design, random mutagenesis and/or adaptive evolution have been the best strategies to improve the yield of PA in propionibacterium. We have previously used genome shuffling (GS) to obtain a recombinant strain capable of producing PA at a yield of $0.55 \mathrm{~g} / \mathrm{g}$ which was close to the target yield of $0.6 \mathrm{~g} / \mathrm{g}$ [5-7]. Developed in the early 2000s, GS is a rapid phenotypic improvement technique based on protoplast fusion [8, 9]. GS relies on multiple combinatorial recombination events in wellconserved regions of the genomes [5] of the parental strains leading to the desired phenotype. The technique has recently been reviewed in detail by [10]. Success heavily depends on finding appropriate screening methods to select for the superior phenotype.

In Propionibacterium, PA biosynthesis is closely linked to energetics. The Wood-Werkman cycle is involved in generating ATP, and balancing redox [11]. As a key biosynthetic pathway of energy metabolism, we were able to correlate PA production with faster growth rate. At the same time, faster growth rate is generally influence by the more efficient energetics. Cells regulate their metabolism through intracellular concentration of energy-linked metabolites. For example, imbalanced AMP, ADP, ATP, cAMP and c-di-AMP trigger mutations in the central carbon metabolism [12]. Such example shows that in response to a metabolic imbalance, cells respond by upregulating alternative pathways. One example of such a pathway is the methylglyoxal pathway which is used to regulate the concentration of imbalanced metabolites [13]. For example, in $E$. coli, induction of the methylglyoxal pathway has been observed as a response for glucose-6-phosphate deregulation [14-16]. Methylglyoxal is produced from dihydroxyacetone phosphate and can be induced by high concentrations of the latter. Reports suggest that the methylglyoxal pathway relieves cells from stress by elevating levels of sugar phosphates [17].

The last decade has also seen rapid advances in highthroughput analytics for strain characterization [18], opening new avenues for understand genotypic changes leading to improved phenotypes. Here, we used a systematic approach to understand the genomic changes leading to a commercially viable process for PA production. The new strain obtained by genome shuffling was obtained from a combination of various strains of Propionibacteria [5]. Genomics, metabolomics and transcriptomics were then used to understand the mutations leading to the improved phenotype. A systematic molecular characterization of the phenotype revealed three key mutations. The analysis was complemented with the design of a nonstructured growth-model $[19,20]$. The model was used to design a feeding strategy resulting in $70 \mathrm{~g} / \mathrm{L}$ of PA, enabling further reduction of downstream purification costs. The process was economically assessed using a revised economic model to predict if the current biological process will be feasible at a $170 \mathrm{kta}$ (thousand tons per year) scale.

\section{Methods \\ Strains}

To access genomic diversity, genome shuffling (GS) was performed using $P$. acidipropionici F3E8 (previously obtained using GS and the wild-type strains $P$. acidipropionici ATCC 55737 and P. acidipropionici ATCC 4875 [5]), P. acidipropionici ATCC 4875, P. acidipropionici ATCC 4965, P. intermedium ATCC 14072 and P. jensenii ATCC 9617. Wild-type strains were selected from a collection of 17 strains previously characterized on sucrose [7]. All strains were kept at $-80^{\circ} \mathrm{C}$ using glycerol (20\%) as cryoprotectant.

\section{Media}

Except when otherwise specified, the PAM medium used contained yeast extract $(10 \mathrm{~g} / \mathrm{L})$, trypticase soy $(5 \mathrm{~g} / \mathrm{L})$, $\mathrm{K}_{2} \mathrm{HPO}_{4}(0.05 \mathrm{~g} / \mathrm{L}), \mathrm{MnSO}_{4}(0.05 \mathrm{~g} / \mathrm{L})$, and sucrose $(40 \mathrm{~g} / \mathrm{L})$. Agar $(15 \mathrm{~g} / \mathrm{L})$ was added to PAM plates. $80 \mathrm{~g} / \mathrm{L}$ instead of $40 \mathrm{~g} / \mathrm{L}$ was used in instrumented fermenters for batch cultures. The feeding solution of fed-batch cultures consisted in PAM media fivefold concentrated and a sugar concentration of $350 \mathrm{~g} / \mathrm{L}$. Sucrose was always autoclaved separately. The chemically defined medium (CDM) contained: sucrose $(20,000 \mathrm{mg} / \mathrm{L})$, $\mathrm{FeSO}_{4} \cdot 7 \mathrm{H}_{2} \mathrm{O} \quad(10 \mathrm{mg} / \mathrm{L}), \quad \mathrm{Fe}\left(\mathrm{NO}_{3}\right)_{2} \cdot 9 \mathrm{H}_{2} \mathrm{O} \quad(1 \mathrm{mg} / \mathrm{L})$, $\mathrm{K}_{2} \mathrm{HPO}_{4}(100 \mathrm{mg} / \mathrm{L}), \mathrm{KH}_{2} \mathrm{PO}_{4}(500 \mathrm{mg} / \mathrm{L}), \mathrm{MgSO}_{4} \cdot 7 \mathrm{H}_{2} \mathrm{O}$ $(500 \mathrm{mg} / \mathrm{L}), \mathrm{MnSO}_{4}(10 \mathrm{mg} / \mathrm{L}), \mathrm{CaCl}_{2} \cdot 6 \mathrm{H}_{2} \mathrm{O}(10 \mathrm{mg} / \mathrm{L})$, $\mathrm{NaH}_{2} \mathrm{PO}_{4} \cdot \mathrm{H}_{2} \mathrm{O}(1597.5 \mathrm{mg} / \mathrm{L}), \mathrm{CoCl}_{2} \cdot 6 \mathrm{H}_{2} \mathrm{O}(10 \mathrm{mg} / \mathrm{L})$, $\mathrm{Na}_{2} \mathrm{HPO}_{4}(3675 \mathrm{mg} / \mathrm{L})$, biotin $(0.2 \mathrm{mg} / \mathrm{L})$, riboflavin $(2 \mathrm{mg} / \mathrm{L})$, thiamine hydrochloride $(1 \mathrm{mg} / \mathrm{L})$, vitamin $\mathrm{B} 12$ $(0.2 \mathrm{mg} / \mathrm{L})$, and pantothenic acid $(2 \mathrm{mg} / \mathrm{L})$ and 12 amino acids. The 12 amino acids used were arginine $(200 \mathrm{mg} / \mathrm{L})$, asparagine $(2000 \mathrm{mg} / \mathrm{L})$, cysteine $(200 \mathrm{mg} / \mathrm{L})$, glutamine $(200 \mathrm{mg} / \mathrm{L})$, histidine $(200 \mathrm{mg} / \mathrm{L})$, leucine $(200 \mathrm{mg} / \mathrm{L})$, methionine $(200 \mathrm{mg} / \mathrm{L})$, phenylalanine $(200 \mathrm{mg} / \mathrm{L})$, proline $(200 \mathrm{mg} / \mathrm{L})$, serine $(200 \mathrm{mg} / \mathrm{L})$, tryptophan $(200 \mathrm{mg} / \mathrm{L})$ and tyrosine $(200 \mathrm{mg} / \mathrm{L})$.

\section{$\mathrm{pH}$ gradient plates}

The $\mathrm{PA} / \mathrm{pH}$ gradient plates were prepared using PAM agar supplemented with $5 \mathrm{~g} / \mathrm{L}$ of PA salt adjusted to $\mathrm{pH}=3$ or $\mathrm{pH}=6.5$ using square plates $(100 \times 100 \mathrm{~mm})$. The plates were prepared by lifting the plates $0.5 \mathrm{~cm}$ and by pouring the neutral $\mathrm{pH}$ agar first. Once the first layer was solidified, the plate was placed horizontally, and the PAM agar at low $\mathrm{pH}$ was added. Plates were incubated overnight at room temperature to allow for the formation of the $\mathrm{pH}$ gradient. The $\mathrm{pH}$ gradient was confirmed with $\mathrm{pH}$ strips indicators. 


\section{Protoplast formation, fusion, and regeneration}

GS was performed as described in our previous study [5]. Protoplast formation buffer (PFB) was made from $(\mathrm{g} / \mathrm{L})$ : sodium succinate (40.5), sucrose (42.75), and $\mathrm{MgCl}_{2}$ (1.9). PFB was dissolved in one litre of Tris $-\mathrm{HCl} 0.05 \mathrm{~mol} / \mathrm{L}$ at $\mathrm{pH}$ 7.1. Regeneration buffer (RB) was made from $(\mathrm{g} / \mathrm{L})$ : yeast extract (10), trypticase soy (5), $\mathrm{KH}_{2} \mathrm{PO}_{4}$ (1.5), $\mathrm{K}_{2} \mathrm{HPO}_{4}$ (2.5), and BSA (5). The media were adjusted to $\mathrm{pH}$ 7. For the protoplast preparation, cells were grown for $24 \mathrm{~h}$ in PAM media supplemented with $40 \mathrm{~g} / \mathrm{L}$ of glucose and $1 \%$ of glycine. Cells were then conditioned in PAM media containing $1 \%$ of glycine and $120 \mathrm{~g} / \mathrm{L}$ of glucose for an extra $24 \mathrm{~h}$. After at least ten generations, cells were washed twice using PBS and fixed to an A600 of 0.2 in a lysozyme solution containing $15 \mathrm{mg} / \mathrm{mL}(600,000 \mathrm{U} / \mathrm{mL})$ in PFB. Cell walls were digested in a $125 \mathrm{~mL}$ flask for two $\mathrm{h}$ at $120 \mathrm{rpm}$ and $40{ }^{\circ} \mathrm{C}$. Protoplasts were detected in a light microscope using the $100 \times$ oil immersion objective and counted using a haemocytometer. When appropriate, protoplasts were regenerated in $\mathrm{RB}$ ( $\mathrm{pH} 7$ for $48 \mathrm{~h}$ at $32{ }^{\circ} \mathrm{C}$ ). For the protoplast fusion, to motivate recombination, protoplasts were treated with UV light (36 W at $253.7 \mathrm{~nm}$ to a distance of $30 \mathrm{~cm}$ ) for $0.5 \mathrm{~min}$ or were treated with heat at $60^{\circ} \mathrm{C}$ for $2 \mathrm{~h}$. Cells were mixed, centrifuged and re-suspended in $500 \mu \mathrm{L}$ of PFB. Then, 500 $\mu \mathrm{L}$ of PEG $6000(80 \%)$ with $20 \mathrm{mmol} / \mathrm{L} \mathrm{CaCl}_{2}$ was added. Fusion conditions were $\mathrm{pH} 7.1$, time $30 \mathrm{~min}$, and temperature $32{ }^{\circ} \mathrm{C}$. After fusion, $5 \mathrm{~mL}$ of PFB was added and centrifuged at $3500 \mathrm{rpm}$ for $5 \mathrm{~min}$. Protoplasts were washed twice with $5 \mathrm{~mL}$ of PFB and re-suspended in $1 \mathrm{~mL}$ of RB.

\section{GS and strain selection}

Strain diversity was created by shuffling the wild-type strains $P$. acidipropionici ATCC 4875, P. acidipropionici ATCC 4965, $P$. intermedium ATCC 14072, and $P$. jensenii ATCC 9617. Separately, the strain P. acidipropionici 4875 was shuffled with the other three wild-type Propionibacterium strains. Cells were selected from the acidic side of $\mathrm{pH} / \mathrm{PA}$ gradient plates. In total, three rounds of genome shuffling were performed with each set of strains. Next, another three rounds of GS were performed with the two libraries of strains, the parental strains $P$. acidipropionici ATCC 4875, P. acidipropionici ATCC 4965, P. intermedium ATCC 14072, P. jensenii ATCC 9617, and the mutant $P$. acidipropionici F3E8. Finally, the new recombinants were isolated by serial dilutions in PAM media agar plates. Plates were incubated in anaerobic jars containing AnaeroGen sachets. Oxoid strip anaerobic indicators were used to confirm anaerobiosis. Individual recombinants were randomly selected and screened in a 96-well plate containing $100 \mu \mathrm{L}$ of PAM media at $\mathrm{pH} 5$ and $25 \mathrm{~g} / \mathrm{L}$ of PA. Growth was monitored using a microplate reader (FLUOStar Omega, BMG Labtech, Mornington, Victoria, Australia) adapted to maintain anaerobic conditions through a continuous injection of nitrogen. The selection criteria were based on an acid tolerance improvement which was determined by an acidic ratio comparison between the new strains and the wild typeratios were calculated by dividing the specific growth rate under acidic conditions over specific growth rate under non-acidic conditions. The best performing strains (Additional file 1: Table S1) were scaled up to $250 \mathrm{~mL}$ serum bottles with a working volume of $100 \mathrm{~mL}$. Serum bottles were incubated using an orbital shaker incubator (Multitron, Infors-HT, Bottmingen, Switzerland) at an agitation rate of $100 \mathrm{rpm}(2.5 \mathrm{~cm}$ orbit $)$ and a working temperature at $32^{\circ} \mathrm{C}$ for $96 \mathrm{~h}$.

\section{Bioreactor fermentations}

Fermentations were performed using 2-L Applikon fermenters with a working volume of $1 \mathrm{~L}$ for batch cultures. Fermenters were equipped with probes and controllers for $\mathrm{pH}$, dissolved oxygen, temperature, and agitation. The agitation rate was controlled with two Rushton impellers at $300 \mathrm{rpm}$. The $\mathrm{pH}$ was controlled at 6.5 using $10 \mathrm{M}$ $\mathrm{NaOH}$. The temperature of the culture was maintained at $32{ }^{\circ} \mathrm{C}$ using an electric jacket. Before inoculation, the fermenters were sparged with $\mathrm{N}_{2}$ for at least $15 \mathrm{~min}$. A constant head space $\mathrm{N}_{2}$ flow was kept for the entire fermentation at a flow rate of $0.3 \mathrm{~L} / \mathrm{min}$. Cultures were activated under sterile conditions in a $1.5 \mathrm{~mL}$ Eppendorf tubes containing $1 \mathrm{~mL}$ of PAM media inoculated with $0.8 \%(\mathrm{v} / \mathrm{v})$ of a glycerol stock. Inoculums were grown for $24 \mathrm{~h}$ at $32^{\circ} \mathrm{C}$. Cultures were transferred into a $15 \mathrm{~mL}$ Falcon tube containing $14 \mathrm{~mL}$ of PAM media and allowed to grow for $24 \mathrm{~h} .5 \%(\mathrm{v} / \mathrm{v})$ of this culture was used to inoculate $250 \mathrm{~mL}$ serum bottles containing $100 \mathrm{~mL}$ of PAM media and allowed to grow for an additional $24 \mathrm{~h}$. Cells from the serum bottles growing in mid-exponential phase were used to inoculate fermenters at an initial A600 of 0.3. Fed-batch cultures were performed using the same culture conditions at a working volume of $0.7 \mathrm{~L}$.

\section{Model development for fed-batch design}

The construction of the batch and fed-batch models was adapted from [19]. The model was first developed as a batch culture and extrapolated to a fed-batch system. The parameters of the batch model were obtained from the fermentation in PAM medium using $80 \mathrm{~g} / \mathrm{L}$ of initial sucrose concentration. The following assumptions were made:

1. Sucrose is the only limiting carbon source.

2. There is no nitrogen limitation. 
3. PA and acetic acid (AA) are the only inhibitory metabolites.

4. The $\mathrm{pH}$ is known and controlled throughout the fermentation at $\mathrm{pH}=6.5$.

\section{Batch model}

The differential mass balance Eqs. (1)-(8) describe the dynamic of propionic acid production in batch fermentation as follows:

$$
\begin{aligned}
& \frac{\mathrm{d} X}{\mathrm{dt}}=u X \quad \text { (biomass) } \\
& \frac{\mathrm{d} S}{\mathrm{dt}}=-\mathrm{qs} X \quad \text { (sucrose) }
\end{aligned}
$$

$$
\frac{\mathrm{dPA}}{\mathrm{dt}}=\left[K 1 u+\beta_{\mathrm{pa}}\right] X \quad(\text { propionic acid })
$$

$$
\frac{\mathrm{dPYR}}{\mathrm{dt}}=\left[K 2 u+\beta_{\mathrm{pyr}}-K 3 \frac{\mathrm{PYR}}{\mathrm{PYR}+K_{\mathrm{pyr}}}\right] X \quad(\text { pyruvic acid })
$$

$$
\frac{\mathrm{dAA}}{\mathrm{dt}}=\left[K 4 u+\beta_{\mathrm{aa}}+K 5 \frac{\mathrm{PYR}}{\mathrm{PYR}+K_{\mathrm{pyr}}}\right] X \quad \text { (acetic acid) }
$$

$$
\frac{\mathrm{dSA}}{\mathrm{dt}}=\left[K 6 u+\beta_{\mathrm{sa}}+K 7 \frac{\mathrm{PYR}}{\mathrm{PYR}+K_{\mathrm{pyr}}}\right] X \quad \text { (succinic acid) }
$$

$$
\mathrm{qs}=\mathrm{rs}_{\max }\left(\frac{S}{K_{\mathrm{s}}+S}\right)\left(\frac{\text { kipa }}{\text { kipa }+\mathrm{PA}}\right)\left(\frac{\text { kiaa }}{\text { kiaa }+\mathrm{AA}}\right)
$$

(specific substrate consumption)

$$
u=\left(\mathrm{qs} Y_{\mathrm{xs}}\right)-\left(\mathrm{ms} Y_{\mathrm{xs}}\right) \quad(\text { specific growth rate })
$$

Equation (1) represents the growth rate and Eq. (8) its specific rate $(\mu)$. The latter equation was adapted from the Leudking and Piret expression. Equation (2) represents the consumption rate of sucrose and Eq. (7) represents its specific rate which considers inhibition by PA and AA. PA, pyruvate (PYR), AA, and succinic acid (SA) production rates are represented by Eqs. (3), (4), (5), and (6), respectively; they consider growth associated $(K)$ and non-growth associated production parameters $(\beta)$. The Eqs. (5) and (6) also describe the consumption of pyruvate generated by Eq. (4) to produce AA, and SA, respectively.

\section{Fed-batch model}

The batch model was extrapolated to a fed-batch culture to design the feeding profile. High PA production and sugar accumulation below $40 \mathrm{~g} / \mathrm{L}$ were the criteria to design parameters for the fed-batch feeding strategy. The fed-batch model was represented with Eqs. (9)(16). To obtain these equations, a differential equation to represent volume $(V)$ and calculate the factor dilution $(D)$ were added to the Eqs. (1)-(6).

$$
\frac{\mathrm{d} x}{\mathrm{dt}}=u X-D X \quad \text { (biomass) }
$$

$$
\frac{\mathrm{d} S}{\mathrm{dt}}=-\mathrm{qs} X+D(S \mathrm{o}-S) \quad(\text { sucrose })
$$

$$
\frac{\mathrm{dPA}}{\mathrm{dt}}=\left[K 1 u+\beta_{\mathrm{pa}}\right] X-D \mathrm{PA} \quad(\text { propionic acid })
$$

$$
\begin{aligned}
\frac{\mathrm{dPYR}}{\mathrm{dt}}= & {\left[K 2 u+\beta_{\mathrm{pyr}}-K 3 \frac{\mathrm{PYR}}{\mathrm{PYR}+K_{\mathrm{pyr}}}\right] X } \\
& -D P Y R \quad(\text { pyruvic acid })
\end{aligned}
$$

$$
\begin{aligned}
\frac{\mathrm{dAA}}{\mathrm{dt}}= & {\left[K 4 u+\beta_{\mathrm{aa}}+K 5 \frac{\mathrm{PYR}}{\mathrm{PYR}+K \mathrm{pyr}}\right] X } \\
& -D A A \quad \text { (acetic acid) }
\end{aligned}
$$

$$
\frac{\mathrm{dSA}}{\mathrm{dt}}=\left[K 6 u+\beta_{\mathrm{sa}}+K 7 \frac{\mathrm{PYR}}{\mathrm{PYR}+K_{\mathrm{pyr}}}\right] X
$$$$
\text { -DSA (succinic acid) }
$$

$\frac{\mathrm{d} V}{\mathrm{dt}}=F \quad$ (flow rate)

$$
D=F / V \quad \text { (factor dilution) }
$$

\section{Reliability of the model}

The coefficient of determination $\left(R^{2}\right)$ was used to determine the reliability of the model. The $R^{2}$ was calculated as follows:

$$
\begin{aligned}
& R^{2}=\frac{1}{m} \sum_{j=1}^{m}\left(1-\frac{\mathrm{SSE}}{\mathrm{SST}}\right) \\
& \mathrm{SSE}=\sum_{i=1}^{n} \Delta_{i}^{2}
\end{aligned}
$$




$$
\begin{aligned}
& \mathrm{SST}=\sum_{i=1}^{n}\left(y_{i}-\bar{y}\right)^{2} \\
& \bar{y}=\frac{1}{n} \sum_{i=1}^{n} y_{i}
\end{aligned}
$$

\section{Parameters estimation}

Excluding the $K_{\mathrm{s}}$ value, the package SBPDgui of the System Biology Toolbox 2 (SBTOOLBOX2) was used to determine the parameters of the model [21]. The $K_{\mathrm{s}}$ value of Eq. 7 was determined experimentally using data from serum bottle fermentations in PAM medium at different concentrations of sucrose.

\section{Calculation of fermentation parameters}

Specific growth rate $(\mu)$ was calculated at the mid-exponential phase. Specific growth rate calculations in 96-well plates were performed using the program GrowthRates [22]. For consistency, volumetric productivity $\left(P_{\mathrm{v}}\right)$ was calculated for the same time interval (ranging from 15 to $30 \mathrm{~h}$ ). Yield $\left(Y_{\mathrm{ps}}\right)$ was calculated using the total PA produced over the consumed substrate. PA:AA and PA:SA ratios were calculated using total organic acid production. The PA:AA and PA:SA ratios are indication of efficiency, in which the higher the ratios the lower is the production of the by-products AA and SA, respectively. The specific consumption rate of sucrose $(q s)$ and the specific production rate of PA $(q p)$ were computed at mid-exponential phase multiplying specific growth rate by the linear correlations of sugar or PA with biomass.

\section{Intracellular $\mathrm{pH}$ measurement $(\mathrm{pHi})$}

Intracellular $\mathrm{pH}(\mathrm{pHi})$ was measured using the method adapted from [23]. Fluorescence of 2',7'-bis-(2carboxyethyl)-5(and 6)-carboxyfluorescein acetoxymethyl ester (BCECF AM) was used to measure pHi. BCECF $\mathrm{AM}$ is a $\mathrm{pH}$-sensitive fluorescein derivative probe with a dual-excitation ratio. Briefly, cells $(2 \mathrm{~mL}$ with a A600 of 2) were centrifuged (12,000 rpm, $1 \mathrm{~min})$ and washed with $50 \mathrm{mM}$ HEPES-K buffer ( $\mathrm{pH}$ 8). The pellet was resuspended in $2 \mathrm{~mL}$ of the same buffer and incubated with $1 \mu \mathrm{L}$ of $1 \mu \mathrm{M}$ BCECF AM for $20 \mathrm{~min}$ at $32{ }^{\circ} \mathrm{C}$. After, cells were washed with $50 \mathrm{mM}$ potassium phosphate buffer ( $\mathrm{pH} 7)$. The pellet was re-suspended in the same buffer and $50 \%$ of the suspension was filtered. Fluorescence intensities were performed in a fluorescence spectrophotometer with an excitation spectrum of $490 \mathrm{~nm}$ (pH sensitive) and $440 \mathrm{~nm}$ (pH-insensitive). The emission was at $535 \mathrm{~nm}$. The ratio of the emission intensity at 490 and 440 of both the suspension $(S)$ and filtrate $(F)$ was determined as follows: $R=\left(S_{490}-S_{440}\right) /\left(F_{490}-F_{440}\right)$. This ratio and a calibration curve were used to calculate the $\mathrm{pHi}$.

The calibration curve was determined for each strain as follows. Valinomycin and nigericin (Sigma) were added to each strain (A600 of 2) to a final concentration of $50 \mu \mathrm{M}$ to maintain equilibration of $\mathrm{pHi}$ with extracellular $\mathrm{pH}$ (pHex). The cultures were then incubated at $32{ }^{\circ} \mathrm{C}$ for 20 min. Cells (2 mL with an A600 of 2) were centrifuged, washed and re-suspended in $2 \mathrm{~mL}$ of buffer at $\mathrm{pH} 4,5,6$, 7 , or 8 (50 mM citrate buffer, $\mathrm{pH} 4$ and 5; $50 \mathrm{mM}$ phosphate buffer, $\mathrm{pH} 6,7$ and 8). After, $1 \mu \mathrm{L}$ of $1 \mu \mathrm{M}$ BCECF AM was added and incubated for $20 \mathrm{~min}$ at $32{ }^{\circ} \mathrm{C}$. After the incubation, cells were washed and re-suspended using the respective buffer. Finally, 50\% of the suspension was filtered, and the fluorescence determination and ratio calculation were performed as mentioned above.

\section{Analytics}

The absorbance of the culture was measured at $600 \mathrm{~nm}$ using a Biochrom Libra S12 UV/Vis spectrophotometer. Organic acids, carbohydrates, and alcohol were quantified by ion-exclusion chromatography as described elsewhere [24].

\section{DNA sequencing, de novo assembly, annotation, and comparison}

Genomic DNA was extracted using PureLink Genomic DNA Mini kit (Invitrogen Cat. No. K1820-01) and quantified using Nanodrop 1000 (Thermo Scientific) and Qubit dsDNA BR assay kit (Life Technologies Cat. No. Q32850). The quality of the DNA was determined by running a $1 \%$ agarose gel with DNA gel stain SYBR safe (Life Technologies Cat. No. S33102). The gel was visualized with a ChemiDoc MP system (Bio-Rad). The PacBio sequencing platform was used to obtain the complete genome of the new recombinant strain. The PacBio library preparation was performed using the protocol for $20 \mathrm{~Kb}$ selected with the BluePippin system. The sequencing chemistry was the release P6-C4 by PacBio and loaded by magnetic beads. The genome assembly was performed with the SMRT portal. This portal was also used to align the reads and call the variants of the sequenced genome. Finally, the RAST and SEED viewer servers were used to annotate and visualize the assembled genome, respectively [25, 26]. Genome-to-genome distance calculator was used to determine similarity between two whole genome sequences [27]. Mauve was used to align multiple genome sequences and trace back genomic mutations [28]. Blast was used to extract specific genomic regions [29]. The genome was submitted to NCBI and assigned the accession number GenBank CP031057. 


\section{Intracellular metabolites extraction}

Cells sampled at mid-exponential phase were used for intracellular metabolomics analyses as described in [30-33]. Metabolites extraction was performed with 50\% acetonitrile $(\mathrm{ACN})$. Briefly, 1-20 ODs $(1 \mathrm{OD}=1 \mathrm{~mL}$ of a culture with an OD of 1) were harvested and centrifuged at $20,172 g$ for $2 \mathrm{~min}$ at room temperature. The supernatant was then discarded, and the pellet was resuspended in $50 \% \mathrm{ACN}$. This solution was vortexed for $10 \mathrm{~s}$ every $2 \mathrm{~min}$ for three times and centrifuged for $3 \mathrm{~min}$ at $4{ }^{\circ} \mathrm{C}$ at 20,172g. After, the supernatant was placed into a tube and frozen at $-80{ }^{\circ} \mathrm{C}$ before being freeze dried. Finally, the powder was resuspended in $0.5 \mathrm{~mL}$ of MilliQ water. Intracellular metabolites of the central carbon metabolism were analysed by LC-MS and intracellular amino acids by HPLC (method described above). Metabolite concentrations were standardized using dry cell weight values. The factor to convert A600 to dry cell weight (g/L) was 0.29 for P. acidipropionici ATCC 55737 and 0.25 for P. acidipropionici WGS7.

\section{Statistical analyses of intracellular metabolomics}

Metabolomics data were normalized and analysed for statistical significance using the $\mathrm{R}$ Package "metabolomics" [34].

\section{RNA extraction, sequencing, and analyses}

Cells sampled at mid-exponential phase were used for RNA extraction as described in [35]. Briefly, 50 ODs (1 $\mathrm{OD}=1 \mathrm{~mL}$ of a culture with an OD of 1 ) were harvested and centrifuged at $4000 \mathrm{~g}$ for $10 \mathrm{~min}$ at room temperature. The supernatant was removed, and $5 \mathrm{~mL}$ of RNA later reagent was added to the pellet. After $8-24 \mathrm{~h}$ of incubation at $4{ }^{\circ} \mathrm{C}$, the RNA later was removed by centrifugation and the pellet stored at $-80{ }^{\circ} \mathrm{C}$ for further use. RNeasy ${ }^{\circledR}$ Mini Kit (Qiagen) was used to extract the RNA and the RNA Clean and Concentrator-25 Kit (Zymo) to clean it. Next, the RNA was enriched depleting the ribosomal RNA with the Ribo-Zero Magnetic Kit (Illumina). The samples were cleaned and concentrated with the RNA Clean and Concentrator-5 Kit (Zymo). The quality of the RNA was evaluated by a Bioanalyzer. Finally, the samples were sequenced using the Illumina platform 100 bp Pair End. Tophat, Cufflinks, and CuffDiff were used to align the RNA-seq reads against the reference genome $P$. acidipropionici ATCC 55737 [36], normalize and annotate the transcripts, and evaluate the differential expression, respectively [37]. The cutoff for significant differentially expressed genes was twofold change and $q<0.05$. The raw transcriptomic data and complete differential expression list (also found in Additional file 2) were deposited in the Gene Expression Omnibus data repository under the accession number GSE86950.

\section{Results and discussion}

Propionibacterium fermentation is inherently inhibited by acid accumulation that ultimately results in growth arrest [38]. Previously, immobilized cells and extractive fermentation systems have been used to improve production with limited success [6, 39-42]. Due to scalability problems using immobilized bed reactors, the best alternative is to develop an improved biocatalyst able to tolerate acidic conditions. Such phenotypes can be obtained using GS. We recently obtained a strain capable of producing PA with a yield of $0.55 \mathrm{~g} / \mathrm{g}$ of glucose using GS [5]. As part of that study, ten strains obtained through GS were sequenced. The analysis showed a correlation between the improved phenotype and acid tolerance. Therefore, to further enhance acid tolerance, we used GS and a PA/pH gradient strategy for screening for higher producers. Firstly, we fused $P$. acidipropionici ATCC 4875 with $P$. acidipropionici ATCC 4965, P. intermedium ATCC 14072, and P. jensenii ATCC 9617. The strains obtained were then fused again with our previously obtained mutant strain P. acidipropionici F3E8 (Fig. 1) [5].

Strains were then characterized using 96-well plates containing $25 \mathrm{~g} / \mathrm{L}$ of $\mathrm{PA}$ and a $\mathrm{pH}$ of 5 . The screening resulted in 13 candidates that were grown in serum bottles (Additional file 1: Table S1). Six out of the thirteen strains had a higher PA yield relative to F3E8. All six strains grew to a higher cell density. The top-three producing strains were moved to instrumented fermenters, and the best strain was selected (hereafter named WGS7). The strain was characterized using a multiomics approach which has been shown to help elucidating links between phenotype and genotype.

As shown in Table 1 and in Fig. 2, WGS7 had an improvement of $37 \%, 85 \%, 43 \%$, and $80 \%$ in the PA yield, PA:AA ratio, growth rate, and volumetric productivity, respectively. The PA:AA improvement was the main contributor for the reduction in cost of the PA downstream purification in WGS7 [1]. The PA:SA ratio was unchanged $(p>0.05)$. We also observed an improvement in the intracellular $\mathrm{pH}$ gradient $(\Delta \mathrm{pH}=$ internal $\mathrm{pH}$-extracellular $\mathrm{pH})$. The strain WGS7 had a $\Delta \mathrm{pH}=1.27$ compared to the wild type which had a $\Delta \mathrm{pH}=0.43$ (Table 1 ). Improvements in $\Delta \mathrm{pH}$ have been reported to improve acid tolerance in other Propionibacterium strains [23]. A feeding profile was then used to increase PA production, designed using a non-structured model. The feeding strategy was designed to keep sucrose concentrations below $40 \mathrm{~g} / \mathrm{L}$ in order to maintain the high PA yields observed in optimal batch conditions (Figs. $2 \mathrm{~b}$ and $3 \mathrm{~b}$, respectively). The fermentation data presented in Fig. $2 \mathrm{~b}$ were used to determine the parameters for the mathematical model (Additional file 3: Table S5). 


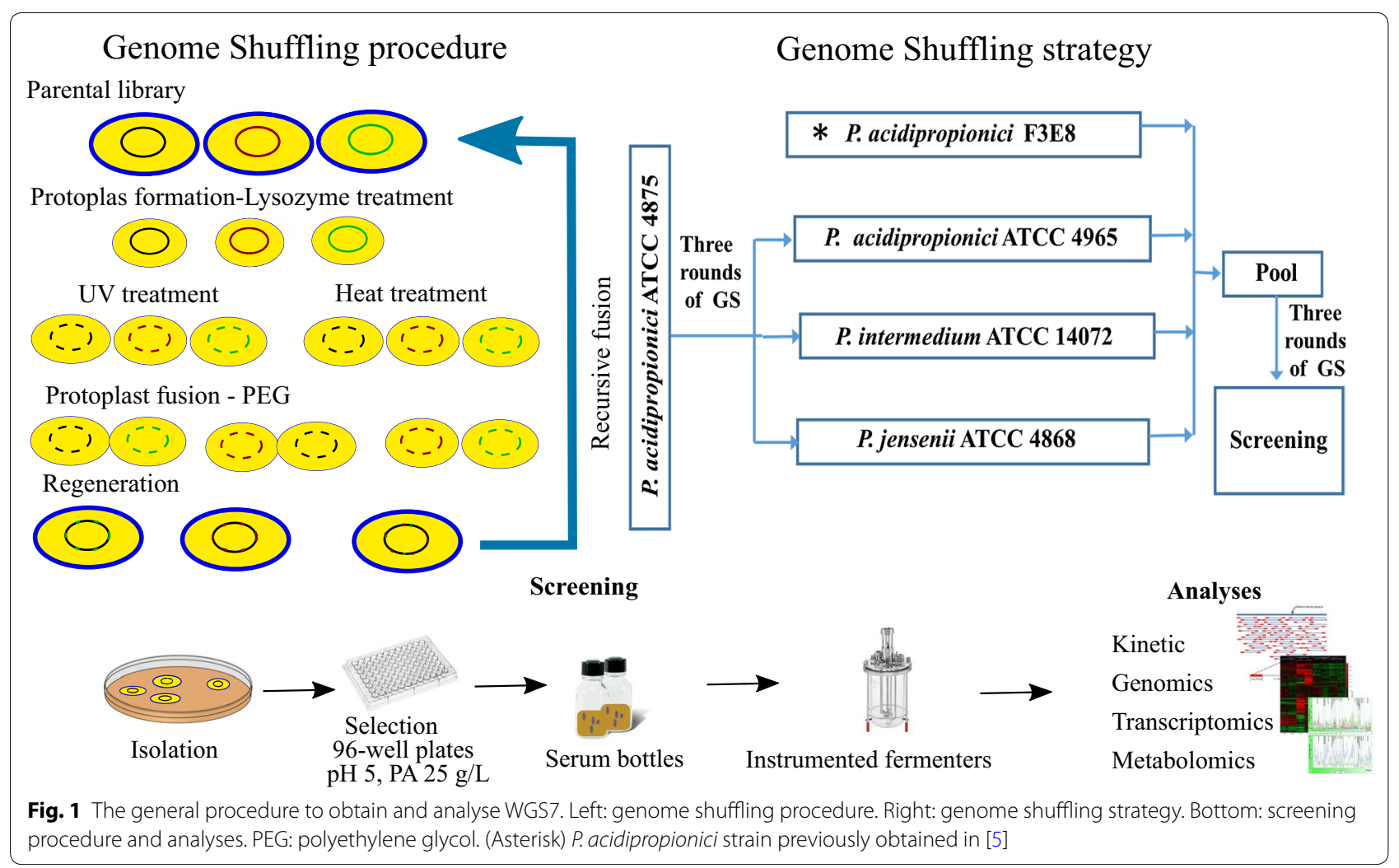

Table 1 Parameters for P. acidipropionici ATCC 55737 and P. acidipropionici WGS7 grown in 2-L fermenters

\begin{tabular}{lcccccc}
\hline Strain & ${ }^{+}$Yps $(\mathbf{g} / \mathbf{g})$ & $\mathbf{P A}: \mathbf{S A}(\mathbf{g} / \mathbf{g})$ & ${ }^{+} \mathbf{P A}: \mathbf{A A}(\mathbf{g} / \mathbf{g})$ & ${ }^{\mathbf{a}+} \boldsymbol{P}_{\mathbf{v}}(\mathbf{g} / \mathbf{L} \mathbf{h})$ & ${ }^{+} \mathbf{\Delta p H}$ & ${ }^{+} \mathbf{F i n a l ~ P A}(\mathbf{g} / \mathbf{L})$ \\
\hline P. acidipropionici ATCC 55737 & $0.45 \pm 0.03$ & $6.28 \pm 0.94$ & $2.95 \pm 0.35$ & $0.530 \pm 0.21$ & $0.43 \pm 0.04$ & $26.28 \pm 1.88$ \\
P. acidipropionici WGS7 & $0.62 \pm 0.01$ & $6.19 \pm 0.23$ & $5.45 \pm 0.41$ & $0.955 \pm 0.15$ & $1.27 \pm 0.10$ & $44.21 \pm 0.93$ \\
\hline
\end{tabular}

$\triangle \mathrm{pH}: \mathrm{pHi}-\mathrm{pHext}$ (pHi: internal $\mathrm{pH}$; pHext: external $\mathrm{pH})$

a Calculated during the range of time: $15-30 \mathrm{~h}$

$+p$ value $<0.05$

The comparison between the experimental data and the simulation for fed-batch culture had a $R^{2}$ of 0.96 (Fig. 3b), suggesting a high accuracy of the model to predict the production of PA in WGS7. The $R^{2}$ for the batch culture at high initial sugar concentration $(130 \mathrm{~g} / \mathrm{L})$ was 0.90 (Fig. 3a). This value suggests issues in the model to accurately predict PA at high sugar concentrations. In the fed-batch culture, WGS7 had a 58\% increase in PA production compared to its optimal PA production in batch culture (Figs. 2b, 3b, and Additional file 3: Table S6). The WGS7 fed-batch culture, producing $70 \mathrm{~g} / \mathrm{L}$ of PA, enables for the first time, an economically viable bioprocess using Propionibacterium spp.

\section{Comparative genomics}

To evaluate similarities between the strains used for GS, we used the genome-to-genome distance calculator
[27]. As expected, high genomic similarities were found between the $P$. acidipropionici strains with a similitude of $86.86 \% \pm 3.58 \%$, which corresponded to a genomic distance of $0.016 \pm 0.004$. Comparatively, the similarity between P. intermedium ATCC 14072 and $P$. jensenii ATCC 9617 was $90.70 \%$, which corresponds to a genomic distance of 0.010 . On the other hand, the similarity between the $P$. acidipropionici strains and the other Propionibacterium spp. was only $26.83 \% \pm 1.21 \%$, which corresponded to a genomic distance of $0.163 \pm 0.006$.

The best strain obtained using GS, WGS7, was sequenced using PacBio RS II and assembled using the SMRT Portal. The $3.16 \mathrm{Mb}$ genome was annotated using RAST [25], which found 3333 CDS and 65 RNAs. Using the SMRT portal, the closest relative found was $P$. acidipropionici ATCC 55737 (hereafter denoted ATCC55737). As such, ATCC55737 was used for comparison hereafter. 

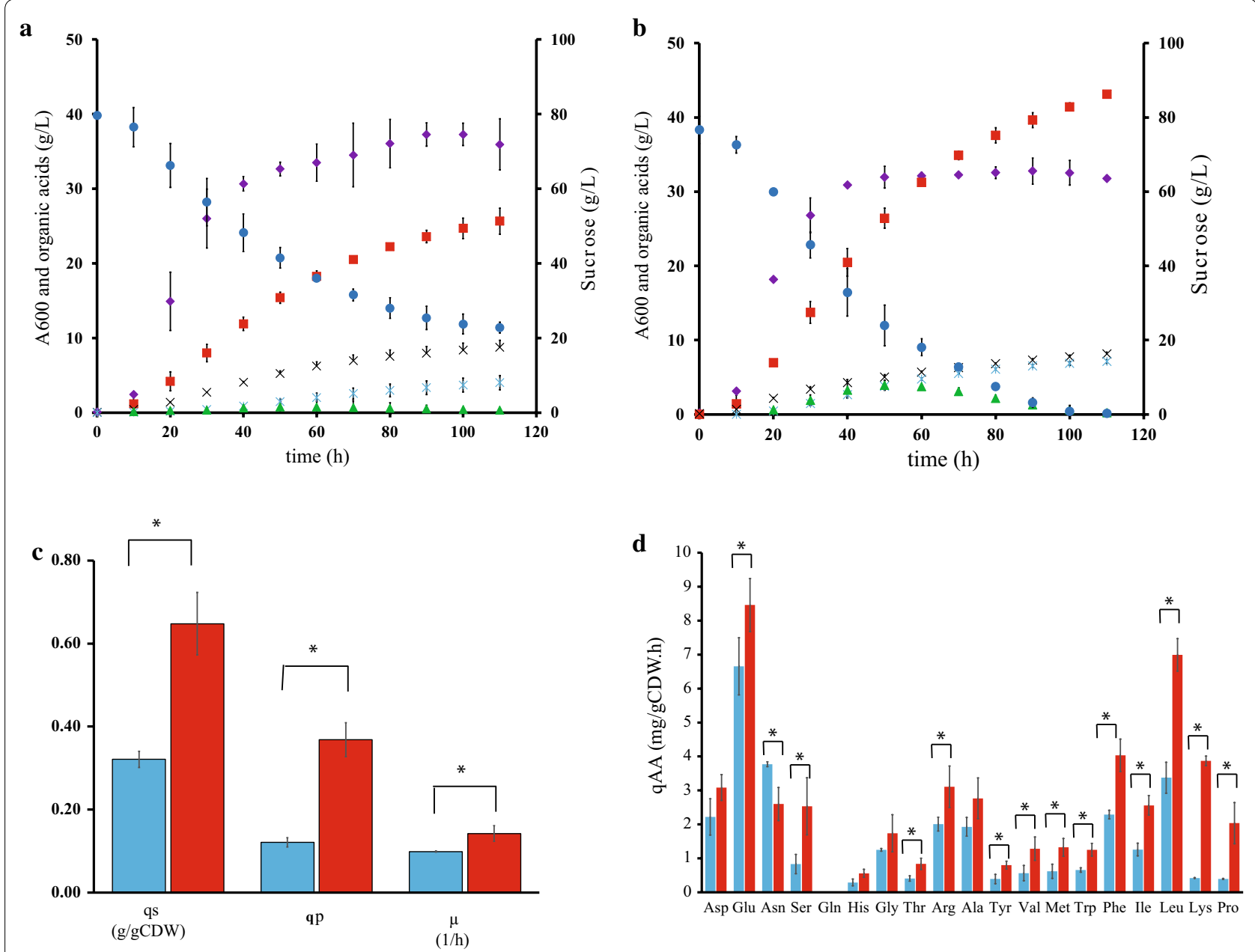

Fig. 2 Fermentation profile in 2-L fermenters for the closest parental strain, P. acidipropionici ATCC 55737, and the new strain obtained through genome shuffling, P. acidipropionici WGS7. a Fermentation profile for P. acidipropionici ATCC 55737, b fermentation profile for P. acidipropionici WGS7. Absorbance: purple; propionic acid: red; glucose: blue; succinic acid: light blue; acetic acid: black; pyruvate: green. c Specific consumption rate of sucrose (qs), specific production rate of PA $(q p)$, and the specific growth rate $(\mu)$. $\mathbf{d}$ Specific consumption rates of the free amino acids presented in the PAM medium. Light blue bars: P. acidipropionici ATCC 55737. Red bars: P. acidipropionici WGS.7. The data represent the average of two biological replicates for each strain. The specific rates were calculated in the mid-exponential phase

The genomic comparison found 17 SNPs and seven INDELs (Additional file 4: Figure S2 and Additional file 5: Table S3). The genomic regions with mutation in WGS7 were aligned with the other strains used for GS. The comparison suggests that two mutations in WGS7 came from the wild-type strains used for GS. The mutation G1917729A was also found in P. acidipropionici ATCC4875 and P. acidipropionici ATCC4965, and the mutation A3335969G was found in all wild-type strains used for GS (Additional file 6: Figures S4, S5). The other mutations, found in WGS7, could not be linked to any of the other strains and, therefore, their origin remains elusive. It is possible that the other mutations are coming from adaptive laboratory evolution in response to the acid challenge, which is a common technique routinely used in industry and academia for strain improvement [38].

\section{Linking metabolomics}

To better understand the links between phenotype and genotype, a systems-level characterization, previously shown to be a useful tool to characterize links between genotype and phenotype [23, 39, 40], was performed. Extracellular metabolites were measured across the fermentation time course (Fig. 2). The growth rate, sucrose, amino acids uptake rates and the PA production rate were calculated from the exponential growth phase. WGS7 had a $96 \%$ higher sucrose uptake rate and a $216 \%$ 

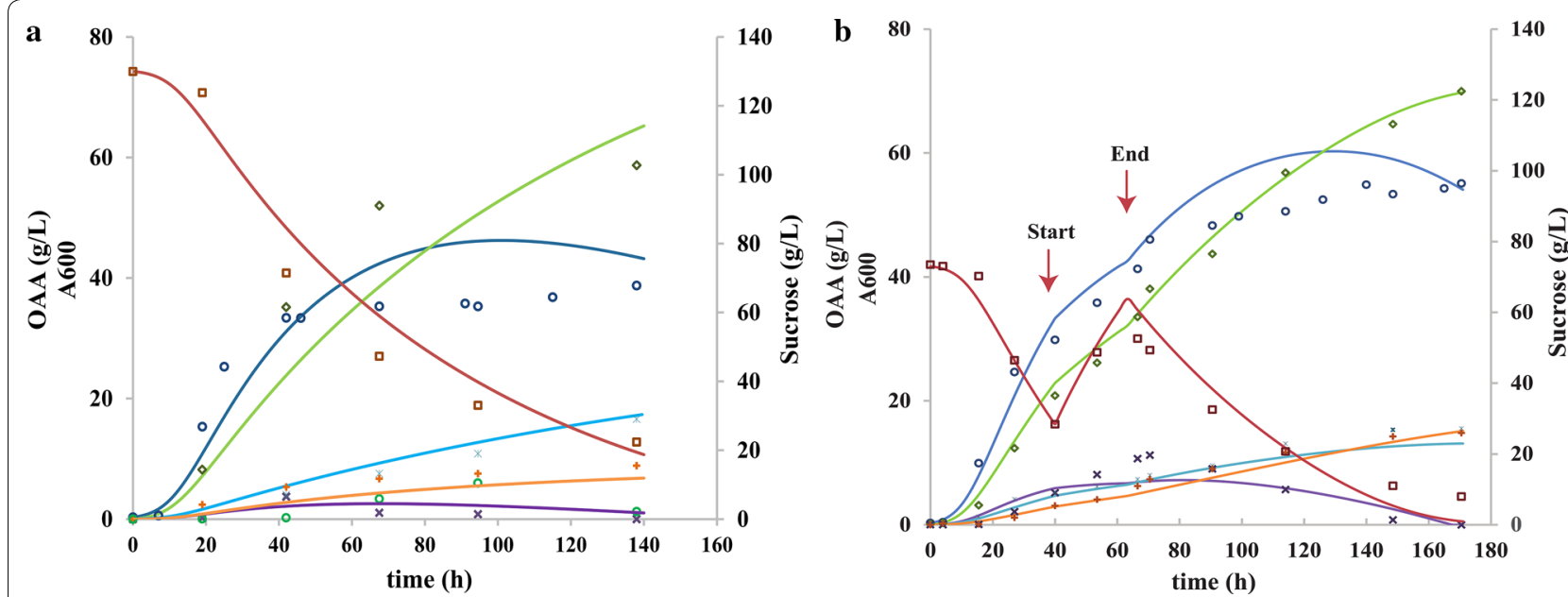

Fig. 3 Fermentation profile of 2-L bioreactors with P. acidipropionici WGS7. a Batch culture with $130 \mathrm{~g} / \mathrm{L}$ of sucrose. b Fed-batch culture with a feeding solution of $5 \times$ the PAM media and a constant feeding rate of $0.0066 \mathrm{~L} / \mathrm{h}$ from time $40 \mathrm{~h}$ (start) to $64 \mathrm{~h}$ (end). For both figures: continuous line indicates model simulation and markers indicate experimental data. Absorbance: blue; propionic acid: light green; sucrose: red; succinic acid: light blue; acetic acid: orange; pyruvate: purple; lactate: green. Experimental absorbance: blue circle; experimental propionic acid: light green lozenge; experimental sucrose: red square; experimental succinic acid: light blue asterisk; experimental acetic acid: orange plus sign; experimental pyruvate: black multiplication sign. oaa: organic acids; experimental lactic acid: light green circle. No simulation data are shown for lactic acid

higher specific PA production rate (Fig. 2c) compared to ATCC55737. All the sugar was depleted in WGS7 within $100 \mathrm{~h}$, whereas ATCC55737 only consumed 69\% of the total sugar provided. A mutation, G1917729A, was found in the promoter region of an $A B C$ sugar transporter (Table 2). Mutation G1917729A in WGS7 seems to come from either $P$. acidipropionici ATCC4875 or P. acidipropionici ATCC4965 (Additional file 6: Figure S4). This gene was found overexpressed $\left(\log _{2} 2.2, q<0.05\right)$ in the transcriptomics data (Fig. 4). In agreement with the data, the sucrose uptake rate was increased in WGS7 (Fig. 2c). Upregulation of sugar transporters is commonly used to enhance production in metabolic engineering. Many studies have previously overexpressed sugar transporters to enhance production. For example, transporters have been overexpressed in E. coli to improve sugar consumption and enhance production of several metabolites [43, 44].

Sixty-four intracellular metabolites, extracted in midexponential phase, were analysed by LC-MS or HPLC.
Six intracellular metabolite concentrations were found to be statistically significant $(p<0.05)$ using the R Package "metabolomics" between the strains compared. From these significant intracellular metabolites, the concentration for serine (Ser) and glycine (Gly) was decreased. The concentrations for alanine (Ala), dihydroxyacetone phosphate (DHAP), ribulose-5-phosphate (R5P) and lactate (Lac) were increased (Fig. 4; Additional file 7: Figure S1 and Table S2).

The genomic analysis found the mutation C2293187T in an ABC polar amino acid transporter (Table 2). Polar amino acids include arginine, lysine, aspartate, glutamine, asparagine, glutamate, serine, threonine, tyrosine, cysteine, methionine, and tryptophan. All those amino acids, except for aspartate and asparagine, were consumed faster in WGS7 than in the wild type (Fig. 2d). Several other investigations have suggested that amino acids metabolism can be closely linked to acid tolerance mechanisms [23]. Here, we observed an improvement in intracellular pH in WGS7 compared to the wild

Table 2 Mutations selected in this study to understand high PA production in WGS7

\begin{tabular}{|c|c|c|c|c|c|c|}
\hline Genome coordinate $^{a}$ & Type & Reference & Alternate & Gene function & Origin & Remark \\
\hline $1,917,729$ & SNP & G & A & $\begin{array}{l}\text { Multiple sugar } A B C \text { transporter, } \\
\text { substrate-binding protein }\end{array}$ & $\begin{array}{l}\text { ATCC } 4965 \text { or } \\
\text { ATCC } 4875\end{array}$ & Promoter \\
\hline $1,487,806$ & SNP & C & $\mathrm{T}$ & Cytochrome c-type biogenesis & E & $\mathrm{R} 134 \mathrm{Q}$ \\
\hline $2,293,187$ & SNP & C & $\mathrm{T}$ & Amino acid $A B C$ transporter & E & Silent \\
\hline
\end{tabular}

SNP single nucleotide polymorphism, E elusive

a Genome coordinate in P. acidipropionici ATCC 55737. ATCC4965 P. acidipropionici ATCC 4875; ATCC4875 P. acidipropionici ATCC 4965. Silent: no change in amino acid 


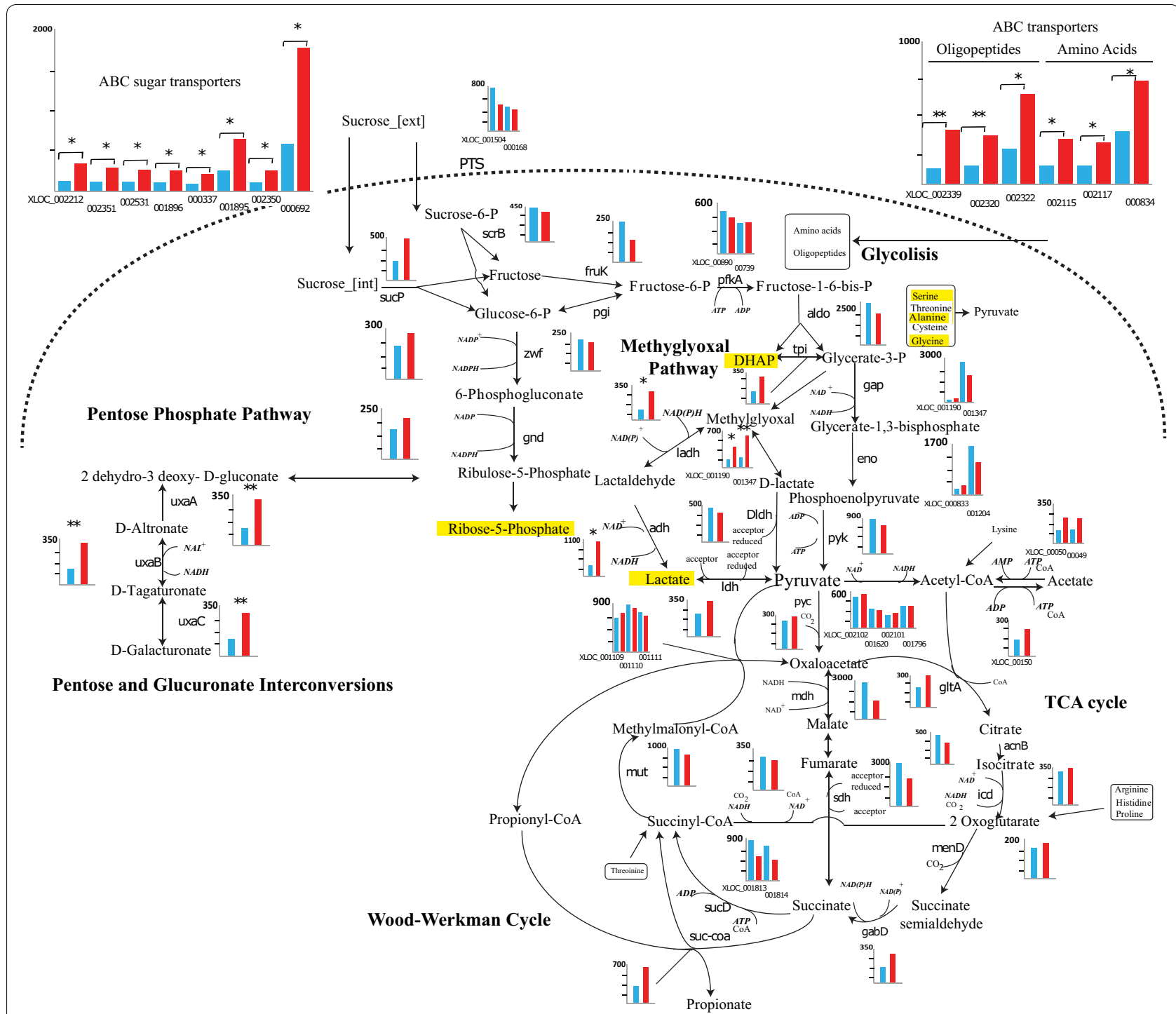

Fig. 4 Metabolic pathways representation of the central carbon metabolism of P. acidipropionici. Bar charts represent RNA-seq data in FPKM. Light blue bars are for P. acidipropionici ATCC 55737 and red bars for P. acidipropionici WGS7. Significance from the Cufflink analysis is indicated with asterisk, where ${ }^{*} q<0.05,{ }^{* *} q<0.01$. Metabolites in yellow were found with an increased concentration in WGS7 $(p<0.05)$. For clarity, the gene IDs name can be found in Additional file 9: Table $\$ 4$

type. In agreement with that observation, arginine, glutamate, lysine, and serine were consumed faster in the complex medium in the WGS7 strain (Fig. 2d). To test their involvement in acid tolerance, each amino acid was added to the CDM separately in both strains. The addition of arginine increased 13\% the final PA titre in WGS7 compared to only $3 \%$ in the wild type (Additional file 8 : Figure S3). Arginine is metabolized through the arginine deiminase (ADI) pathway in $P$. acidipropionici. Other investigators have reported that overexpression of the arginine deiminase pathway increased PA production by tenfold in $P$. jensenii [45]. However, RNA-seq data showed that the arginine/ornithine antiporter gene was downregulated in WGS7 and that the pathway is not differentially transcribed (Additional file 2). Downregulation suggests that the ADI pathway is unlikely to be involved in acid tolerance in the new strain and that the polar amino acid transporter is likely to be transporting a different amino acid. Lysine consumption rate in WGS7 was eightfold higher than in the wild-type strain. Lysine supplementation increased $41 \%$ the PA production in WGS7 compared to $7 \%$ in the wild type. Similarly, serine 
supplementation increased the PA titre 36\% in WGS7 compared to $12 \%$ in the wild type. Alanine addition did not improve PA production in WGS7. Such results suggest a clear involvement of lysine and serine on PA production in WGS7. It is possible, while highly speculative, that the $\mathrm{ABC}$ polar amino acid transporter may be involved in lysine and serine transport. Lysine decarboxylation is a well reported acid tolerance mechanism [41-43], which has clearly improved in WGS7 relative to the control strain. In contrast, the involvement of serine in the improved phenotype remains elusive and further investigation to elucidate its involvement is needed.

\section{Comparative transcriptomics}

RNA-sequencing was used to compare the transcriptional profile of the strains. Our analyses identified 2406 transcribed genes, of which 76 were significantly different $(q<0.05)$. Thirteen genes were downregulated and 63 were upregulated. Based on the RNA-sequencing data, a metabolic pathway illustrating the changes in the metabolism is presented in Fig. 4. The figure includes transcripts measurements for the central carbon metabolism genes, for sugar transport, amino acid transport, the methylglyoxal pathway, the pentose phosphate pathway and the glucuronate interconversion pathway which are the main pathways showing changes in transcription.

Interestingly, WGS7 showed changes in transcription for eight $A B C$ sugar transporters, three $A B C$ amino acid transporters and three $\mathrm{ABC}$ oligopeptides transporters (Fig. 4 and Additional file 2 and Additional file 5: Table S3). The nitric oxide reductase gene (XLOC_000683) was also found to be differentially transcribed $\left(\log _{2} 1.30, q<0.05\right)$. Genes belonging to the methylglyoxal pathway ladh, adh, XLOC_002338, and XLOC_002219 were also significantly transcribed in WGS7 (Fig. 4 and Additional file 9: Table S4). Three genes involved in the pentose and glucuronate interconversion were also significantly upregulated including altronate dehydratase $(u x a A)$, altronate oxidoreductase $(u x a B)$, and unronate isomerase $(u x a C)$. The arginine/ornithine antiporter gene was downregulated in WGS7 $\left(\log _{2} 1.35\right.$, $q<0.05)$. The flavin reductase gene (XLOC_001914) and the nitric oxide reductase gene (XLOC_000683) were also found significantly upregulated $\left(\log _{2} 1.31, q<0.05\right.$ and $\log _{2} 1.30, q<0.05$, respectively). Our analysis found global changes at the transcriptional level, which clearly contributed to the improved phenotype. However, the link between the genomic changes and the transcriptomics changes remains unclear. Nonetheless, as illustrated in Fig. 4, the transcriptional changes can be linked to the improved phenotype by contributing to better nutrient transport and by creating detoxifying pathways for improved metabolism.

\section{Energy metabolism}

As mentioned earlier, WGS7 displayed a clear growth improvement relative to the control strain. Improvement in growth rate is normally linked to better energetics [44, 45]. The mutation C1487806T was found in the Cytochrome $\mathrm{C}$ biogenesis gene (Table 2). Cytochrome $\mathrm{C}$ has been reported to be abundant under anaerobic culture conditions in E. coli [46] and has been associated with anaerobic electron transport through nitrate reductase activity $[3,47]$ in the early $80 \mathrm{~s}$. We found significant upregulation of the nitric oxide reductase gene (XLOC_000683); however, its involvement is unclear. We speculate that this mutation may play a role in intracellular $\mathrm{pH}$ control or stress response as there is a link between nitrate degradation and ammonia; the source of $\mathrm{NO}$ is, however, elusive given the anaerobic conditions. A report suggests that the lactate-pyruvate reaction requires an electron acceptor [3]. Other authors have suggested that cytochrome $\mathrm{C}$ can act as a natural electron transporter in the lactate-pyruvate reaction $[48,49]$. To test this hypothesis, we performed serum bottle fermentations on CDM with $50 \mathrm{mM}$ of exogenous lactate. The exogenous addition of lactate increased PA production by $125 \%$ in the WGS7 strain while only $66 \%$ in the wild type.

An electron transport system in P. acidipropionici is also responsible for the reduction of fumarate in the Wood-Werkman Cycle [3]. Flavin, as flavin adenine dinucleotide (FAD), has been suggested to play a role in the fumarate reductase enzyme [50]. Transcriptomics analyses showed upregulation of the flavin reductase gene (XLOC_001914). This overexpression suggests that the fumarate-succinate is contributing to the increase in PA production because it is associated with ATP generation [50]. To evaluate our hypothesis, we supplemented CDM cultures with $10 \mathrm{mM}$ of fumarate. The addition of fumarate increased PA production by twofold. The fact that PA production in the wild-type was not improved by the exogenous addition of fumarate strengthens our hypothesis of a probable improvement in the electron transport chain in the fumarate-succinate reaction (Additional file 8: Figure S3).

Our transcriptomics study suggests upregulation of genes involved in the methylglyoxal pathway. The methylglyoxal pathway converts glyceraldehyde-3-phosphate into methylglyoxal [51], which generates D-lactate or L-lactate. The methylglyoxal reductase and aldehyde dehydrogenase convert methylglyoxal into lactaldehyde and produce L-lactate. If methylglyoxal enters the glyoxylate pathway, methylglyoxal is converted into D-lactate via lactoylglutathione. Lactate can be converted into pyruvate. The methylglyoxal pathway is activated under high carbon concentrations [13]. The increased sucrose 
uptake rate in WGS7 is likely to have triggered the methylglyoxal pathway (Figs. 2c and 4), a transient low-energy bypass of the lower Embden-Meyerhof-Parnas pathway during abundant carbon source concentrations [13]. Others have suggested that the abundance of intracellular fructose 1,6-diphosphate, glycerate-3-phosphate, or dihydroxyacetone phosphate can activate the methylglyoxal pathway [13]. In agreement with that, WGS7 showed an increased concentration of the dihydroxyacetone phosphate metabolite (Fig. 4; Additional file 7: Figure S1). Using the methylglyoxal pathway, cells have a mechanism to control the rate of energy generation relative to the overall catabolic rate.

\section{Economic evaluation of WGS7}

Prior work has shown that fermentation yield has a substantial impact on the overall economics of biological production of PA [1]. Similarly, Liu et al. [2] have suggested that PA concentration and productivity is critical to achieve a commercially viable bioprocess. The process economics model described in [1] was updated to reflect a yield improvement from 0.55 to $0.62 \mathrm{~g} / \mathrm{g}$ as obtained by WGS7. Data for the Techno-economic analysis were obtained from the data available at Dow AgroSciences and the model used is described in [1]. The model predicts cost of PA production based on the current prices. As shown in Fig. 5, the yield improvement was more than a 15\% cash cost reduction in 2017 and significantly improved the cost-competitiveness being 39\% below the current market value of PA, suggesting commercially viable margin. The net cash costs for PA from the WGS7 process were modelled to be $\sim \$ 0.38 / \mathrm{lb}$. Most importantly, the yield improvement with WGS7 reduces the time at which the fermentation process becomes economically competitive with the "oxo" process from the year 2025 to the year 2020 .

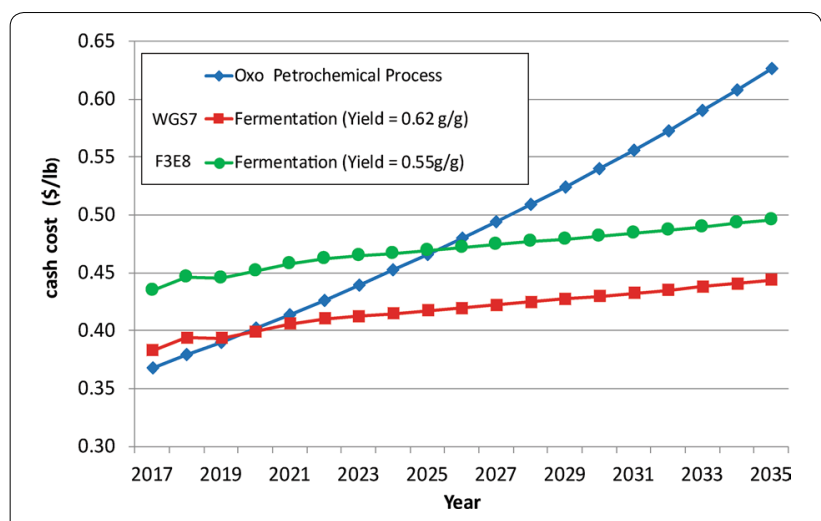

Fig. 5 Cash cost forecast for competing PA routes using WGS7 and F3E8 strains

\section{Conclusions}

Propionibacteria are attractive biocatalysts for the biological production of C3 chemicals. Using GS, we obtained a strain capable of competitively producing PA at $170 \mathrm{kta}$ scale. The fermentation yield obtained resulted in a $15 \%$ reduction in cash cost for bio-derived PA which significantly improves the cost-competitiveness with the oxo-processes. Multiomics comparison revealed genomic mutations possibly responsible for the improved phenotype. Notably, as indicated by RNA-sequencing and metabolomics, an increase in the sucrose uptake rate and an increased in amino acid uptake rate were linked to the new phenotype.

\section{Additional files}

Additional file 1: Table S1. Parameters of the fermentations in serum bottles for some strains used in this study.

Additional file 2. Complete list of differentially expressed genes in transcriptomics.

Additional file 3. Supplementary information for kinetic modelling. Table S5. Kinetic model parameters. Table S6. Parameter of the 2-L fermentation with P. acidipropionici WGS7 in a Batch or Fed-Batch culture.

Additional file 4: Figure S2. Variants detected in the new genome $P$. acidipropionici WGS7 taking as a reference genome P. acidipropionici ATCC 55737.

Additional file 5: Table S3. Variants and copy number variation found in the new strain P. acidipropionici WGS7 using as reference strain P. acidipropionici ATCC 55737.

Additional file 6. Multiple genome alignments of mutations in WGS7 coming from a parental strain. Figure S4. Multiple genome alignment of the genomic regions $50 \mathrm{bp}$ before and $50 \mathrm{bp}$ after the mutation G1917729A was found in WGS7. ATCC55737 P. acidipropionici ATCC 55737; WGS7 P. acidipropionici WGS7; ATCC4875 P. acidipropionici ATCC 4875; ATCC4965 P. acidipropionici ATCC 4965. Position 51 indicates the mutation G1917729A in WGS7 and similarity with the other wild-type strains. This genomic region was not found in P. jensenii ATCC 9617 and P. intermedium ATCC 14072. Figure S5. Multiple genome alignment of the genomic region 50 bp before and $50 \mathrm{bp}$ after the mutation $\mathrm{A} 3335969 \mathrm{G}$ was found in WGS7. ATCC55737 P. acidipropionici ATCC 55737; WGS7 P. acidipropionici WGS7; ATCC4875 P. acidipropionici ATCC 4875; ATCC4965 P. acidipropionici ATCC 4965. P. jensenii ATCC 9617; P. intermedium ATCC 14072. Position 51 indicates the mutation A3335969G in WGS7 and similarity with the other wild-type strains.

Additional file 7: Figure S1. Correlation of intracellular metabolites between the new strain P. acidipropionici WGS7 and the wild-type strain $P$. acidipropionici ATCC 55737. Table S2. $P$-values obtained from metabolomics comparisons.

Additional file 8: Figure $\mathrm{S3}$. Effects of exogenous addition of $50 \mathrm{mM}$ of lactate (LAC), $10 \mathrm{mM}$ of fumarate (FUM), $10 \mathrm{mM}$ of arginine (Arg), $10 \mathrm{mM}$ of lysine (Lys), $10 \mathrm{Mm}$ of serine (Ser), or $10 \mathrm{mM}$ of proline (Pro) in P. acidipropionici ATCC 55737 (light blue bars) and P. acidipropionici WGS7 (red bars). Fermentations were performed by duplicate serum bottle fermentations containing CDM media.

Additional file 9: Table S4. Legend of the main pathways associated to the PA synthesis. 


\begin{abstract}
Abbreviations
PA: propionic acid; AA: acetic acid; SA: succinic acid; GS: genome shuffling; CDM: chemical defined medium; P. acidipropionici: Propionibacterium acidipropionici; PA:AA: ratio propionic acid to acetic acid; PA:SA: ratio propionic acid to succinic acid; NGS: next-generation sequencing; PAM: Propionibacterium acidipropionici culture media; $\mu$ : specific growth rate; $P_{\mathrm{v}}$ : volumetric productivity; $Y_{\text {ps }}$ : propionic acid over glucose yield; CDS: coding sequences; $q_{\mathrm{s}}$ : specific consumption rate of sucrose; $q_{\mathrm{p}}$ : specific production rate of $\mathrm{PA} ; q_{\mathrm{AA}}$ : specific amino acid consumption.
\end{abstract}

\section{Authors' contributions}

$C L F, E M$, and LKN participated in the design of the experiments. CLF performed the experiments. CLF and EM analysed the data and wrote the manuscript. CS and BC developed the techno-economic analyses. All authors read and approved the final manuscript.

\section{Author details}

1 Australian Institute for Bioengineering and Nanotechnology (AIBN), The University of Queensland, Brisbane, QLD 4072, Australia. ${ }^{2}$ Queensland Node of Metabolomics Australia, The University of Queensland, Brisbane, QLD 4072 , Australia. ${ }^{3}$ BioEngineering and Bioprocessing R\&D, Dow AgroSciences LLC, 9330 Zionsville Road, Indianapolis, IN 46268, USA.

\section{Acknowledgements}

The authors acknowledge support from Metabolomics Australia (MA) at The University of Queensland, an NCRIS initiative under Bioplatforms Australia Pty Ltd. We acknowledge Tim McCubbin and Axayacatl Gonzalez Garcia for fruitful discussions. Manuel Plan and Mark Hudson from Metabolomics Australia offered their support throughout all the project.

\section{Competing interests}

The authors declare that they have no competing interests. Dow has commercial interest in the published strain.

\section{Availability of data and materials}

The dataset supporting the conclusions of this article are included within the article and its additional files. RNA-seq data can be found in the Gene Expression Omnibus webpage with accession number GSE86950.

\section{Consent for publication}

Not applicable.

Ethics approval and consent to participate

Not applicable.

\section{Funding}

EM acknowledges support from the Queensland Government for his Fellowship. This study was supported by the University of Queensland and the Australian Research Council through a linkage Grant (LP120100517) with Dow. CLF was supported through a CONACYT scholarship from the Mexican Council for Science and Technology (CONACYT).

\section{Publisher's Note}

Springer Nature remains neutral with regard to jurisdictional claims in published maps and institutional affiliations.

Received: 5 April 2017 Accepted: 3 August 2018

Published online: 13 August 2018

\section{References}

1. Rodriguez BA, Stowers CC, Pham V, Cox BM. The production of propionic acid, propanol and propylene via sugar fermentation: an industrial perspective on the progress, technical challenges and future outlook. Green Chem. 2014;16:1066-76.

2. Liu L, Zhu Y, Li J, Wang M, Lee P, Du G, et al. Microbial production of propionic acid from Propionibacteria: current state, challenges and perspectives. Crit Rev Biotechnol. 2012;32:374-81.
3. Parizzi LP, Grassi MCB, Llerena LA, Carazzolle MF, Queiroz VL, Lunardi I, et al. The genome sequence of Propionibacterium acidipropionici provides insights into its biotechnological and industrial potential. BMC Genomics. 2012. https://doi.org/10.1186/1471-2164-13-562.

4. Tufvesson P, Ekman A, Sardari RRR, Engdahl K, Tufvesson L. Economic and environmental assessment of propionic acid production by fermentation using different renewable raw materials. Bioresour Technol. 2013;149:556-64

5. Luna-Flores CH, Palfreyman RW, Krömer JO, Nielsen LK, Marcellin E. Improved production of propionic acid using genome shuffling. Biotechnol J. 2016. https://doi.org/10.1128/genomea.00248-16.

6. Guan N, Liu L, Zhuge X, Xu Q, Li J, Du G, et al. Genome-shuffling improves acid tolerance of Propionibacterium acidipropionici. In: Tylor JC, editor. Advances in chemistry research. Nova Science Publishers, Inc.: New York; 2012. p. 143-52.

7. Stowers CC, Cox BM, Rodriguez BA. Development of an industrializable fermentation process for propionic acid production. J Ind Microbiol Biotechnol. 2014:41:837-52.

8. Scheinbach S. Protoplast fusion as a means of producing new industrial yeast strains. Biotechnol Adv. 1983;1:289-300.

9. Zhang YX, Perry K, Vinci VA, Powell K, Stemmer WPC, del Cardayré SB. Genome shuffling leads to rapid phenotypic improvement in bacteria. Nature. 2002;415:644-6.

10. Magocha TA, Zabed H, Yang M, Yun J, Zhang H, Qi X. Improvement of industrially important microbial strains by genome shuffling: current status and future prospects. Bioresour Technol. 2018. https://doi. org/10.1016/j.biortech.2018.02.118.

11. Gonzalez-Garcia R, McCubbin T, Navone L, Stowers C, Nielsen L, Marcellin E. Microbial propionic acid production. Fermentation. 2017;3:21. https:// doi.org/10.3390/fermentation3020021.

12. Zhu Y, Pham TH, Nhiep THN, Vu NMT, Marcellin E, Chakrabortti A, et al. Cyclic-di-AMP synthesis by the diadenylate cyclase CdaA is modulated by the peptidoglycan biosynthesis enzyme GImM in Lactococcus lactis. Mol Microbiol. 2016;99:1015-27.

13. Weber J, Kayser A, Rinas U. Metabolic flux analysis of Escherichia coli in glucose-limited continuous culture. II. Dynamic response to famine and feast, activation of the methylglyoxal pathway and oscillatory behaviour. Microbiology. 2005;151:707-16.

14. Ackerman RS, Cozzarelli NR, Epstein W. Accumulation of toxic concentrations of methylglyoxal by wild-type Escherichia coli K-12. J Bacteriol. 1974;119:357-62.

15. Receptor C, Puskas R, Gazdar C, Peterkofsky A. Methylglyoxal-mediated growth inhibition in an Escherichia coli protein mutant. Arch Biochem Biophys. 1983;223:503-13.

16. Kadner RJ, Murphy GP, Stephens CM. Two mechanisms for growth inhibition by elevated transport of sugar phosphates in Escherichia coli. J Gen Microbiol. 1992;138:2007-14.

17. Cooper RA, Anderson A. The formation and catabolism of methyglyoxal during glycolisis in Escherichia coli. FEBS Lett. 1970;11:273-6.

18. Marcellin E, Nielsen LK. Advances in analytical tools for high throughput strain engineering. Curr Opin Biotechnol. 2018;54:33-40.

19. Goswami V, Srivastava AK. Fed-batch propionic acid production by Propionibacterium acidipropionici. Biochem Eng J. 2000:4:121-8.

20. Luna-Flores CH, Ramírez-Cordova JJ, Pelayo-Ortiz C, Femat R, HerreraLópez EJ. Batch and fed-batch modeling of carotenoids production by Xanthophyllomyces dendrorhous using Yucca filifera date juice as substrate. Biochem Eng J. 2010;53:131-6.

21. Schmidt H, Jirstrand M. Systems Biology Toolbox for MATLAB: a computational platform for research in systems biology. Bioinformatics. 2006:22:514-5.

22. Hall BG, Acar H, Nandipati A, Barlow M. Growth rates made easy. Mol Biol Evol. 2014:31:232-8.

23. Guan N, Liu L, Shin H-D, Chen RR, Zhang J, Li J, et al. Systems-level understanding of how Propionibacterium acidipropionici respond to propionic acid stress at the microenvironment levels: mechanism and application. J Biotechnol. 2013;167:56-63.

24. Marcellin E, Behrendorff JB, Nagaraju S, DeTissera S, Segovia S, Palfreyman $\mathrm{R}$, et al. Low carbon fuels and commodity chemicals from waste gasessystematic approach to understand energy metabolism in a model acetogen. Green Chem. 2016;18:3020-8. 
25. Aziz RK, Bartels D, Best AA, DeJongh M, Disz T, Edwards RA, et al. The RAST server: rapid annotations using subsystems technology. BMC Genomics. 2008;9:75.

26. Devoid S, Overbeek R, DeJongh M, Vonstein V, Best AA, Henry C. Automated genome annotation and metabolic model reconstruction in the SEED and Model SEED. Methods Mol Biol. 2013;985:17-45.

27. Auch AF, Klenk HP, Göker M. Standard operating procedure for calculating genome-to-genome distances based on high-scoring segment pairs. Stand Genomic Sci. 2010:2:142-8.

28. Darling ACE, Mau B, Blattner FR, Perna NT. Mauve: multiple alignment of conserved genomic sequence with rearrangements. Genome Res. 2004;14:1394-403.

29. Tatusova TA, Madden TL. BLAST 2 sequences, a new tool for comparing protein and nucleotide sequences. FEMS Microbiol Lett. 1999;174:247-50

30. Licona-Cassani C, Steen JA, Zaragoza NE, Moonen G, Moutafis G, Hodson $\mathrm{MP}$, et al. Tetanus toxin production is triggered by the transition from amino acid consumption to peptides. Anaerobe. 2016. https://doi. org/10.1016/j.anaerobe.2016.07.006.

31. Dietmair S, Hodson MP, Quek LE, Timmins NE, Chrysanthopoulos P, Jacob $\mathrm{SS}$, et al. Metabolite profiling of $\mathrm{CHO}$ cells with different growth characteristics. Biotechnol Bioeng. 2012;109:1404-14.

32. Licona-Cassani C, Marcellin E, Quek LE, Jacob S, Nielsen LK. Reconstruction of the Saccharopolyspora erythraea genome-scale model and its use for enhancing erythromycin production. Antonie Van Leeuwenhoek. 2012;102:493-502.

33. Marcellin E, Nielsen LK, Abeydeera P, Krömer JO. Quantitative analysis of intracellular sugar phosphates and sugar nucleotides in encapsulated streptococci using HPAEC-PAD. Biotechnol J. 2009;4:58-63.

34. De Livera AM, Dias DA, De Souza D, Rupasinghe T, Pyke J, Tull D, et al. Normalizing and integrating metabolomics data. Anal Chem. 2012:84:10768-76.

35. Marcellin E, Mercer TR, Licona-Cassani C, Palfreyman RW, Dinger ME, Steen JA, et al. Saccharopolyspora erythraea's genome is organised in high-order transcriptional regions mediated by targeted degradation at the metabolic switch. BMC Genomics. 2013. https://doi. org/10.1186/1471-2164-14-15.

36. Luna-Flores CH, Nielsen LK, Marcellin E. Genome sequence of Propionibacterium acidipropionici ATCC 55737. Genome Announc. 2016. https:// doi.org/10.1128/genomea.00248-16.

37. Trapnell C, Roberts A, Goff L, Pertea G, Kim D, Kelley DR, et al. Differential gene and transcript expression analysis of RNA-seq experiments with TopHat and Cufflinks. Nat Protoc. 2012;7:562-78.
38. Dragosits M, Mattanovich D. Adaptive laboratory evolution—principles and applications for biotechnology. Microb Cell Fact. 2013;12:64. https:// doi.org/10.1186/1475-2859-12-64.

39. Biot-Pelletier D, Martin VJJ. Evolutionary engineering by genome shuffling. Appl Microbiol Biotechnol. 2014;98:3877-87.

40. Zheng DQ, Chen J, Zhang K, Gao KH, Li O, Wang PM, et al. Genomic structural variations contribute to trait improvement during wholegenome shuffling of yeast. Appl Microbiol Biotechnol. 2013. https://doi. org/10.1007/s00253-013-5423-7.

41. Park Y-K, Bearson B, Bang SH, Bang IS, Foster JW. Internal pH crisis, lysine decarboxylase and the acid tolerance response of Salmonella typhimurium. Mol Microbiol. 1996;20:605-11.

42. Merrell DS, Camilli A. Acid tolerance of gastrointestinal pathogens. Curr Opin Microbiol. 2002;5:51-5.

43. Merrell DS, Camilli A. The cadA gene of Vibrio cholerae is induced during infection and plays a role in acid tolerance. Mol Microbiol. 1999;34:836-49.

44. Utrilla J, Licona-Cassani C, Marcellin E, Gosset G, Nielsen LK, Martinez A. Engineering and adaptive evolution of Escherichia coli for D-lactate fermentation reveals GatC as a xylose transporter. Metab Eng. 2012;14:469-76.

45. Gosset G. Improvement of Escherichia coli production strains by modification of the phosphoenolpyruvate:sugar phosphotransferase system. Microb Cell Fact. 2005. https://doi.org/10.1186/1475-2859-4-14.

46. Peggs D, Boyce S, Luquin MR, Sambrook MA, Biology S. Repression and derepression of cytochrome $\mathrm{c}$ biosynthesis in Escherichia coli. Biochim Biophys Acta. 1963:70:170-2.

47. Liu M-C, Peck HD Jr., Abou-Jaoude A, Chippaux M, LeGall J. A reappraisal of the role of the low potential c-type cytochrome (cytochrome c-552) in nadh-dependent nitrite reduction and its relationship with a co-purified nadh oxidase in Escherichia coli k-12. FEMS Microbiol Lett. 1981:53:333-7.

48. Ogata M, Arihara K, Yagi T. D-lactate dehydrogenase of Desulfovibrio vulgaris. J Biochem. 1981;89:1423-31.

49. Yoshimura T, Matsushima A, Aki K, Kakiuchi K. Formation of a complex between yeast L-lactate dehydrogenase (cytochrome b2) and cytochrome c. Biochim Biophys Acta. 1977;492:331-9.

50. Ingledew WJ, Poole RK. The respiratory chains of Escherichia coli. Microbiol Rev. 1984:48:222-71.

51. Babel W, Hofmann KH. The conversion of triosephosphate via methylglyoxal, a bypass to the glycolitic sequence in methylotrophic yeasts? FEMS Microbiol Lett. 1981;10:133-6.
Ready to submit your research? Choose BMC and benefit from:

- fast, convenient online submission

- thorough peer review by experienced researchers in your field

- rapid publication on acceptance

- support for research data, including large and complex data types

- gold Open Access which fosters wider collaboration and increased citations

- maximum visibility for your research: over $100 \mathrm{M}$ website views per year

At BMC, research is always in progress.

Learn more biomedcentral.com/submissions 